\title{
Mathematical Modelling And Steady-State Simulation Study of Three Phase Squirrel Cage Induction Machine, Using The Dot Convention Technique for Magnetically Coupled Circuit.
}

\author{
Obute K.C. ${ }^{1}$, Enemuoh F.O ${ }^{1}$, Onuegbu J.C. ${ }^{1}$ \\ ${ }^{I}$ Department Of Electrical Engineering Nnamdi Azikiwe University Awka, Anambra State Nigeria
}

\begin{abstract}
This paper presents the mathematical modelling and simulation study of three phase squirrel cage induction machine. This is achieved, using the dot convention technique for magnetically coupled circuit applicable to circuit elements of electrical machines. When two loops (coils), with or without contacts between them affect each other through the magnetic field generated by one of them, they are said to be magnetically coupled when such loops are in a close proximity to each other, the magnetic flux caused by current in one coil links with the other loop, thereby inducing voltage in the later by mutual induction. Based on the notion of mutual induction, we then introduce the circuit element known as transformer. A close examination of the fluxmmf interactions in a poly-phase squirrel cage induction motor shows that, electrically, the machine is a form of transformer. The synchronously-rotating air-gap flux wave in the induction machine is the counterpart of the mutual core flux in the transformer. The rotating field induces emf's of stator frequency in the stator windings and of slip frequency in the rotor windings (for all rotor speeds other than synchronous speed). The induction machine transforms voltages and at the same time changes frequency. When viewed from the stator, all rotor electrical and magnetic phenomena are transformed to stator frequency. The rotor mmf reacts on the stator windings in the same manner as the mmf of the secondary current in a transformer reacts on the primary. Pursuit of this line of reasoning leads to per-phase equivalent circuit for 3-phase induction machines which closely resemble that of the transformer (A.E. Fitzgerald et al (2003)). In terms of operation, the squirrel cage induction machine can be relatively seen as a short-circuited rotating transformer, having much similarity in their steady state equivalent circuits. In the course of developing this paper, the equivalent circuit of the squirrel cage induction machine, from which its steady-state characteristics via simulation/matlab plots could be predicted, is obtained using the magnetically coupling effect of transformer elements.
\end{abstract}

Keyword: Magnetic coupling, mutual induction, self induction, short-circuited rotating transformer, squirrel cage induction machine.

\section{Introduction}

Where a 3-phase supply is available, 3-phase motors are preferred to 1-phase motor in all but the smallest size. The 3 - phase squirrel cage induction motor is more efficient, has a high power factor, better starting properties and are cheaper than the corresponding 1 - phase motor of same size and rating. Supply authorities require 3 phase motors to be used where possible, to prevent unbalanced loads on the mains.

In a 3 - phase squirrel cage induction machine (motor), the magnetic field rotates, and this has the advantage that no external electrical connections to the rotor need be made. Its name is derived from the fact that the current in the rotor is induced by transformer action. That is to say that the current in the rotor is induced by the magnetic field instead of being supplied through electric connection to the supply (John bird (2010)). Hence, the squirrel cage induction motor is also known as rotating transformer. That is, when an e.m.f is supplied to its stator, then as a result of electromagnetic induction, a voltage is induced in its rotor by mutual flux. So an induction motor is termed a transformer, with rotating secondary. Here, primary of transformer resembles stator winding of an induction motor, while the secondary resembles the rotor (Electrical 4 u.com). In its strict analytical configuration, the squirrel cage induction machine shares a related similarity with a transformer, especially in their equivalent circuit representations.

\section{Production of a rotating magnetic field}

The stator of the motor consists of overlapping winding offset by an electrical angle of $120^{\circ}$. When a 3 - phase supply is connected to the stator windings, a rotating magnetic field of constant amplitude in the air-gap which rotates at the synchronous speed is produced. There is relative velocity between the constant amplitude rotating field and the stationary stator winding (Smarajit Ghosh (2017)). So an emf is induced in the stator winding. The magnitude of this induced e.m.f in any one phase is given by;

$\mathrm{Eph}=4.44 \mathrm{f} \mathrm{K}_{\mathrm{w}} \mathrm{N}_{\mathrm{s}} \mathrm{ph} \phi \quad$ volts $\quad \ldots 1$

Where, $f=$ rotational frequency of the supply voltage 
$\mathrm{K}_{\mathrm{w}}=$ winding factor, $\mathrm{N}_{\mathrm{s}} \mathrm{ph}=$ the stator series turns/phase, $\phi=$ flux per pole.

Additionally, in an induction machine (motor), the rotating magnetic field in the air gap rotates at a synchronous speed $\left(\mathrm{N}_{\mathrm{s}}\right)$ given by;

$\mathrm{N}_{\mathrm{s}}=\left(\frac{120 f}{\mathrm{P}}\right) \mathrm{rpm}$

$=\left(\frac{2 f}{\mathrm{P}}\right) \mathrm{rps}$

Where $\mathrm{P}=$ number of stator poles

Since the rotor rotates at a speed $\mathrm{N}_{\mathrm{r}} \mathrm{rpm}$ less than the synchronous speed $\mathrm{N}_{\mathrm{s}}$ in the same direction of the rotating magnetic field, the relative speed $\left(\mathrm{N}_{\mathrm{R}}\right)$ (also known as slip speed) between the rotating magnetic field and the rotor is given by,

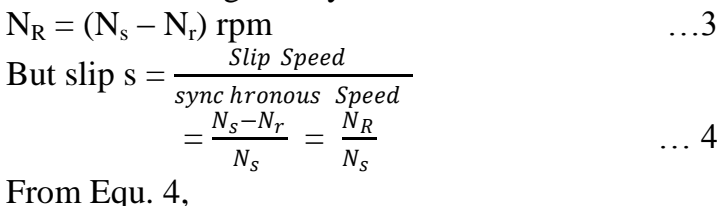

$\mathrm{N}_{\mathrm{r}}=(1-\mathrm{s}) \mathrm{N}_{\mathrm{s}}$

If we let us suppose that the frequency of induced or generated e.m.f in the rotor coil is $f_{r}$ (slip frequency) then, $\mathrm{f}_{\mathrm{r}}=\mathrm{sf}$ Hertz $\ldots 6$

Hence, the e.m.f. induced or e.m.f generated in one rotor coil is given by;

$\mathrm{E}_{\mathrm{r}}=4.44 \mathrm{f}_{\mathrm{r}} \mathrm{N}_{\mathrm{r}} \mathrm{ph} \mathrm{kw} \phi$

$=4.44$ sf $\mathrm{N}_{\mathrm{r}} \mathrm{ph} \mathrm{kw} \phi \quad$ Volts

where $\mathrm{N}_{\mathrm{rph}}=$ rotor turns/phase

Conversely, if the rotor is being rotated at a speed $\left(\mathrm{N}_{\mathrm{r}} \mathrm{rpm}\right)$ in the opposite direction of the rotating field $\left(\mathrm{N}_{\mathrm{s}}\right.$ $\mathrm{rpm})$, the slip is given by the frequency of induced or generated e.m.f in rotor by;

Slip s $=\frac{N_{S}+N_{r}}{N_{S}}$

III. Model of a 3 - phase squirrel cage induction machine (motor).

The development of the model for the 3-phase squirrel cage induction machine was done, using the dot convention technique for magnetically coupled circuit. We will begin with the concept of mutual inductance and tactically introduce the dot convention used for determining the voltage polarities of inductively coupled components. Based on the notion of mutual inductance, the circuit element known as transformer is introduced, from which the idea of the induction machine at stand-still being a static transformer with its secondary winding short-circuited comes into play.

\section{Derivation of 3-phase squirrel cage induction machine steady-state equivalent circuit.}

The 3- phase squirrel cage induction machine (motor) equations and equivalent circuit can be obtained from the equivalent $\mathbf{T}$ circuit of a linear transformer as illustrated below, starting from the time and frequency domain analysis of a circuit containing coupled coils as shown in fig 1 (a/b) below;

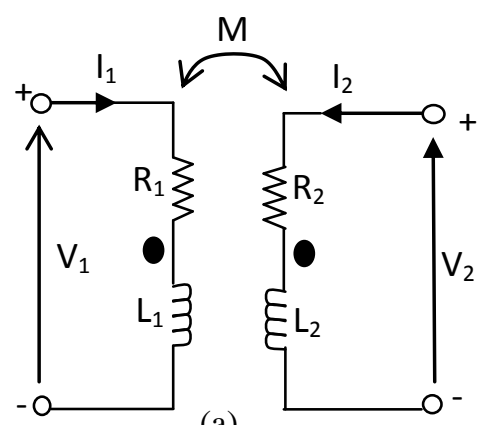

(a)

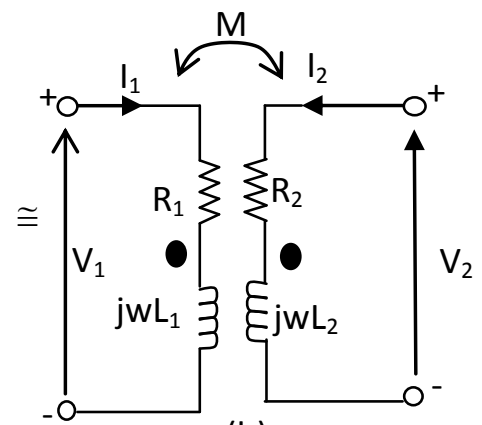

(b)

Fig 1-(a)-Time-domain circuit of the coupled coil

(b) - Frequency- domain circuit of the coupled coil (Charles K. Alexander et al (2007)).

NB: $M$ and $L$ are the Mutual and self inductances of the coils respectively.

From fig $1 \mathrm{~b}$, and analyzing the circuit in the frequency domain by applying KVL to coils 1 and 2 we have; 
$\mathrm{V}_{1}=\left(\mathrm{R}_{1}+\mathrm{jwL} \mathrm{L}_{1}\right) \mathrm{I}_{1}+\mathrm{jwML} \mathrm{L}_{2}$

$\mathrm{V}_{2}=\mathrm{jwMI}+\left(\mathrm{R}_{2}+\mathrm{jwL} \mathrm{L}_{2}\right) \mathrm{I}_{2}$

Putting equation 9 in compact form we have

$\left[\begin{array}{l}\mathrm{V}_{1} \\ V_{2}\end{array}\right]=\left[\begin{array}{cc}\mathrm{R}_{1}+\mathrm{jwL}_{1} j w M \\ j w M & R_{2}+j w L_{2}\end{array}\right]\left[\begin{array}{l}\mathrm{I}_{1} \\ I_{2}\end{array}\right] \ldots 10$

If we consider the imaginary components $\mathrm{L}_{1}$ and $\mathrm{L}_{2}$ as in fig $1(\mathrm{a} / \mathrm{b})$, the circuits boil down to an equivalent circuits of a linear transformer as shown in fig 2 below;

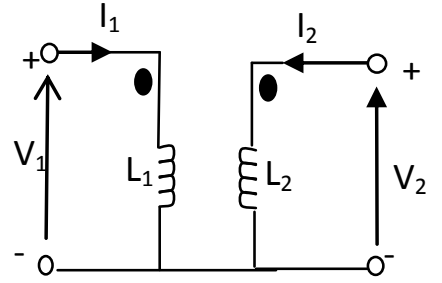

(a)

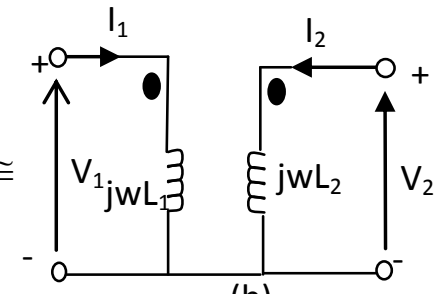

(b)

From fig $2 b$

Fig 2 - Equivalent circuits of linear transformer

$\mathrm{V}_{1}=\mathrm{jwL}_{1} \mathrm{I}_{1}+\mathrm{jwM} \mathrm{I}_{2}$

$\left.\mathrm{V}_{2}=\mathrm{jwMI} \mathrm{I}_{1}+\mathrm{jwL} \mathrm{L}_{2}\right\}$

$\Rightarrow\left[\frac{\mathrm{v}_{1}}{\mathrm{~V}_{2}}\right]=\left[\begin{array}{ll}j w \mathrm{~L}_{1} & j w M \\ j w M & j w L_{2}\end{array}\right]\left[\begin{array}{l}I_{1} \\ I_{2}\end{array}\right]$

Let us suppose that the corresponding equivalent $\mathbf{T}$ circuit of the linear transformer equivalent circuit of fig 2 be given as in fig 3 below;

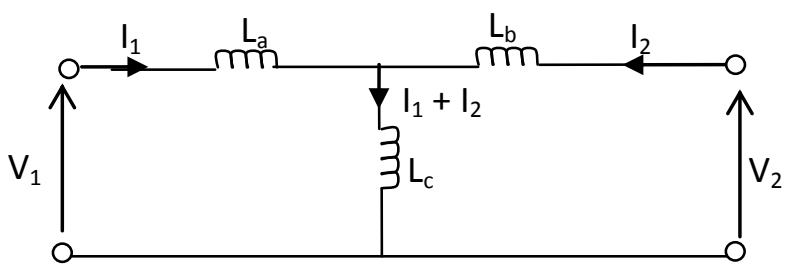

Fig 3 - Equivalent $\mathbf{T}$ circuit of the linear transformer

For the $\mathbf{T}$ network of fig 3,

$\left.\begin{array}{l}\mathrm{V}_{1}=\mathrm{jw}\left(\mathrm{L}_{\mathrm{a}}+\mathrm{L}_{\mathrm{c}}\right) \mathrm{I}_{1}+\mathrm{jwL} \mathrm{L}_{\mathrm{c}} \mathrm{I}_{2} \\ \mathrm{~V}_{2}=\mathrm{jw} \mathrm{L}_{\mathrm{c}} \mathrm{I}_{1}+\mathrm{jw}\left(\mathrm{L}_{\mathrm{b}}+\mathrm{L}_{\mathrm{c}}\right) \mathrm{I}_{2}\end{array}\right\}$

$\Rightarrow\left[\begin{array}{l}\mathrm{V}_{1} \\ V_{2}\end{array}\right]=\left[\begin{array}{ll}j w\left(L_{a}+L_{c}\right) & j w L_{c} \\ j w L_{c} & j w\left(L_{a}+L_{c}\right)\end{array}\right]\left[\begin{array}{l}\mathrm{I}_{1} \\ I_{2}\end{array}\right]$

If the circuits of fig $2 \mathrm{~b}$ and fig 3 are equivalent, then equations 12 and 14 must be identical.

Hence, equating terms in the impedance matrice of equations 12 and 14 leads to;

$\left.\begin{array}{l}\mathrm{jwL}_{1} \cong \mathrm{jw}\left(\mathrm{L}_{\mathrm{a}}+\mathrm{L}_{\mathrm{c}}\right) \\ \Rightarrow \mathrm{L}_{1}=\mathrm{L}_{\mathrm{a}}+\mathrm{L}_{\mathrm{c}} \\ \text { Similarly, jwL } \mathrm{L}_{2} \cong \mathrm{jw}\left(\mathrm{L}_{\mathrm{b}}+\mathrm{L}_{\mathrm{c}}\right) \\ \Rightarrow \mathrm{L}_{2}=\mathrm{L}_{\mathrm{b}}+\mathrm{L}_{\mathrm{c}} \\ \text { Likewise, jwM } \mathrm{jwL}_{\mathrm{c}} \\ \Rightarrow \mathrm{M}=\mathrm{L}_{\mathrm{c}}\end{array}\right\}$

From equation 15 ;

If $\mathrm{M}=\mathrm{L}_{\mathrm{c}}$

$\therefore \mathrm{L}_{1}=\mathrm{La}+\mathrm{M}$, from which;

$$
\mathrm{La}=\mathrm{L}_{1}-\mathrm{M}
$$

Also, $\mathrm{L}_{\mathrm{b}}=\mathrm{L}_{2}-\mathrm{M}$<smiles>C1=CCCCC1</smiles>

By substitution, the equivalent

$\mathbf{T}$ circuit of the linear transformer of fig 3, reduces to; 


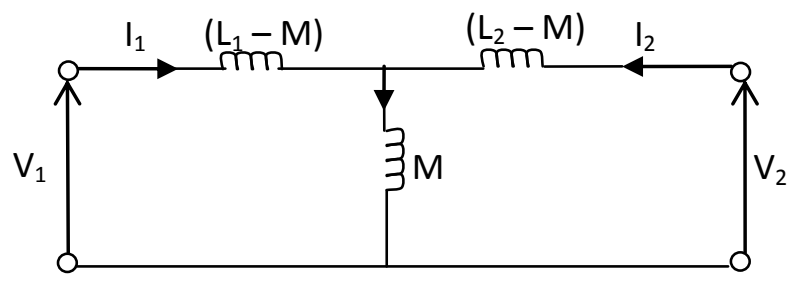

Fig 4 - Equivalent $\mathbf{T}$ circuit of linear transformer with parameters $\left(\mathrm{L}_{1}, \mathrm{~L}_{2}, \mathrm{M}\right)$.

To account for the losses in the coil, the real quantities $R_{1}$ and $R_{2}$ of fig 1 are inserted into fig 4 as below;

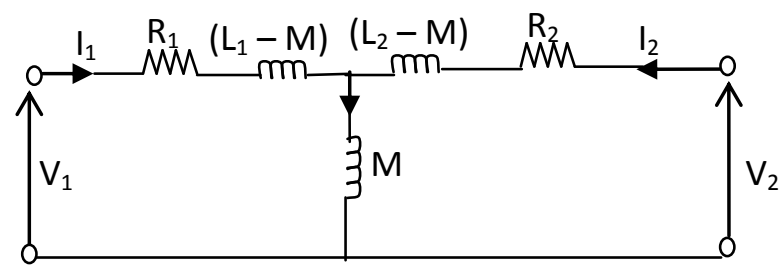

Fig. 5 - Equivalent $\mathbf{T}$ circuit of the linear transformer with real and imaginary quantities.

Obviously, a squirrel cage induction motor at stand-still $(s=1)$ mimics a static transformer with its secondary winding short circuited as in fig 6 , so that $\mathrm{V}_{2}$ of fig 5 becomes zero The equivalent circuit of an induction motor is similar to that of a transformer. The main difference is that the rotor of induction motor rotates and mechanical power is developed (Smarajit Ghosh (2007)).

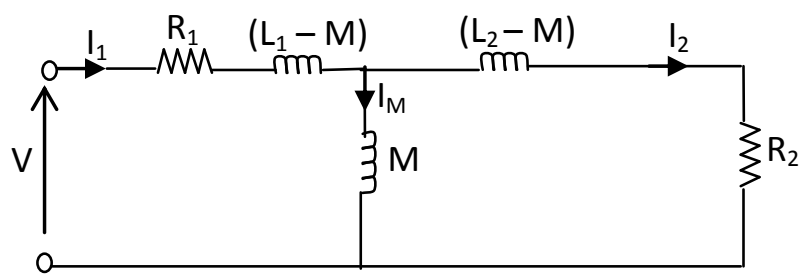

Fig 6 - Per-phase equivalent circuit of squirrel cage induction motor at stand still $(\mathrm{s}=1)$

Under run condition of the motor, $\mathrm{Nr}>0$, and $\mathrm{s}<1$. Hence the load resistance $\mathrm{R}_{2}$ is affected by slip $\mathrm{s}$, as depicted in fig 7.Given that resistance $\left(R_{1}\right)=$ stator winding resistance $\left(R_{s}\right)$, resistance $\left(R_{2}\right)=$ Rotor winding resistance $\left(R_{r}\right)$, Inductance $\left(L_{1}\right)=$ stator winding inductance $\left(L_{s}\right)$, Inductance $\left(L_{2}\right)=$ Rotor winding inductance $\left(\mathrm{L}_{\mathrm{r}}\right)$ and $\mathrm{M}=$ mutual inductance of $\mathrm{L}_{\mathrm{s}}$ and $\mathrm{L}_{\mathrm{r}}$, then fig 6 becomes;

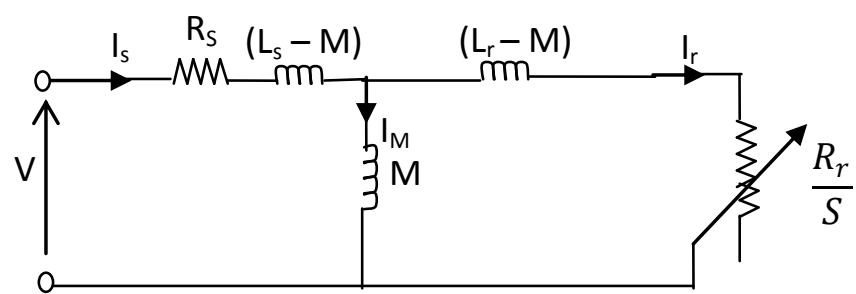

Fig 7 = Per-phase equivalent circuit of squirrel cage induction motor at run condition $(S<1)$.

Table 1.1 - Parameters for the steady state simulation of 3-phase squirrel cage induction motor.

\begin{tabular}{|l|l|}
\hline Parameter & Value \\
\hline $\mathrm{L}_{\mathrm{s}}=\mathrm{L}_{\mathrm{r}}$ & $119.79 \mathrm{mH}$ \\
$\mathrm{M}$ & $114 \mathrm{mH}$ \\
$\mathrm{R}_{\mathrm{s}}=\mathrm{R}_{\mathrm{r}}$ & $1.10 \Omega$ \\
$\mathrm{V}$ & $220 \mathrm{~V}$ \\
$\mathrm{~F}$ & $50 \mathrm{H}_{\mathrm{Z}}$ \\
$\mathrm{P}$ & 2 \\
\hline
\end{tabular}




\section{Power across air-gap, output power and electromechanical torque}

With reference to the equivalent circuit of fig 7 , the power crossing the terminals of the shunt mutual inductance (M) is the electrical power input per phase minus the stator losses (stator copper and iron loss). It is the power that is transferred from the stator to the rotor through the air-gap magnetic field. This is known as the power across the air gap. Its 3 - phase value $\left(\mathrm{P}_{\mathrm{g}}\right)$ is given as;

$\mathrm{P}_{\mathrm{g}}=3\left(\mathrm{I}_{\mathrm{r}}^{2}\right) \frac{R_{r}}{S} \quad$ Watts $\quad \ldots 17$

Similarly, Rotor copper loss $\mathrm{P}_{\mathrm{cr}}=3 \mathrm{I}_{\mathrm{r}}^{2} \mathrm{R}_{\mathrm{r}} \quad$ Watts $\quad \ldots 18$

From equations 17 and 18

$\mathrm{P}_{\mathrm{g}}=\frac{P_{c r}}{S}$

$\Rightarrow \mathrm{P}_{\mathrm{cr}}=\mathrm{sP}_{\mathrm{g}} \quad$ Watts

The mechanical output (gross) power $\left(\mathrm{P}_{\mathrm{m}}\right)$ of the motor is obtained by subtracting equation 19 from 17 as below; $\Rightarrow \mathrm{P}_{\mathrm{m}}=\mathrm{P}_{\mathrm{g}}-\mathrm{P}_{\mathrm{cr}}=3\left(\mathrm{I}_{\mathrm{r}}\right)^{2} \frac{R_{r}}{\mathrm{~S}}-3\left(\mathrm{I}_{\mathrm{r}}\right)^{2} \mathrm{R}_{\mathrm{r}}$

$=3\left(\mathrm{I}_{\mathrm{r}}\right)^{2} \frac{R_{r}}{S}(1-\mathrm{s})$

$\therefore \mathrm{P}_{\mathrm{m}}=\mathrm{P}_{\mathrm{g}}(1-\mathrm{s})$

Similarly, the electromagnetic torque $\left(\mathrm{T}_{\mathrm{e}}\right)$ developed by the motor is given by;

$\mathrm{T}_{\mathrm{e}}=\frac{P_{g}}{\omega_{r}}=\frac{(1-s) P_{g}}{\omega_{s}(1-s)}=\frac{P_{g}}{\omega_{s}}$

Where $\omega_{r}=$ rotor speed in mechanical radian per sec, $\omega_{s}=$ synchronous speed in mechanical radian per second.

$\left.\begin{array}{c}\Rightarrow \mathrm{T}_{\mathrm{e}}=\frac{3\left(I_{r}\right)^{2} \frac{R_{r}}{s}}{\omega_{s}} \mathrm{~N}-\mathrm{m} \\ \mathrm{NB}: \omega_{r}=2 \pi \mathrm{N}_{\mathrm{r}} \\ \omega_{s}=2 \pi \mathrm{N}_{\mathrm{s}}\end{array}\right\}$

More still, the mechanical net power or shaft power $\left(\mathrm{P}_{\mathrm{sh}}\right)=\mathrm{P}_{\mathrm{m}}-$ Mechanical losses (friction and windage losses)

$\Rightarrow$ Output or shaft torque $\left(\mathrm{T}_{\mathrm{sh}}\right)$ of the motor is given by;

$$
\mathrm{T}_{\text {sh }}=\frac{P_{s h}}{(1-s) \omega_{s}} \quad \mathrm{~N}-\mathrm{m} \quad \ldots 23
$$

Equation 21 is an interesting and significant result according to which torque is obtained from the power across the air gap by dividing it with synchronous speed $\left(\omega_{s}\right)$ in $\mathrm{rad} / \mathrm{s}$, as if this power was transferred at synchronous speed.

\section{Torque-slip characteristics}

The torque-slip characteristics of the motor can be studied for better if the per-phase equivalent circuit of fig 7 is slightly modified as in fig 8 below

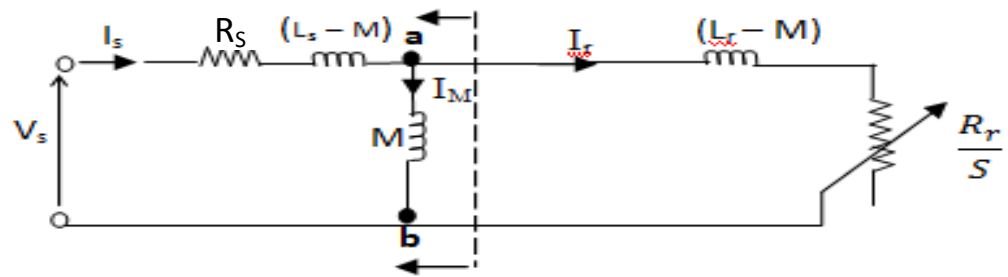

Fig 8 - Modit1ed per-phase equivalent circuit of squirrel cage induction motor at run condition

The expression for torque-slip characteristics is easily obtained by finding the Thevenin equivalent of the circuit of fig 8 , to the left of $\mathbf{a b}$, as shown below;

$\mathrm{Z}_{\mathrm{TH}}=\mathrm{R}_{\mathrm{TH}}+\mathrm{j} \mathrm{X}_{\mathrm{TH}}$

$=\left(R_{\mathrm{S}}+\mathrm{j} X_{(\mathrm{LS}-\mathrm{M})}\right) / / \mathrm{j} \mathrm{X}_{\mathrm{m}}$

$=\frac{\left(R_{S}+j X_{\left(L_{S}-M\right)}\right) j X_{M}}{\left(R_{S}+j X_{\left(L_{S}-M\right)}+j X_{M}\right)}$

$=\frac{\left(R_{S}+j X_{\left(L_{s}-M\right)}\right) X_{M}}{\left(R_{S}+j\left(X_{\left(L_{S}-M\right)}+X_{M}\right)\right.}$

Assuming $\left(X_{(L s-M)}+X_{M}\right) \gg>R_{s}$, then; 
$\mathrm{Z}_{\mathrm{TH}}=\frac{\mathrm{R}_{\mathrm{S}} \mathrm{X}_{\mathrm{M}}}{X_{(L s-M)}+X_{M}}+\frac{\mathrm{j} \mathrm{X}_{(\mathrm{Ls}-\mathrm{M})} \mathrm{X}_{\mathrm{M}}}{\mathrm{X}_{(L s-M)}+\mathrm{X}_{\mathrm{M}}} \quad \Omega \quad \ldots 24$

$\Rightarrow \mathrm{R}_{\mathrm{TH}}=\frac{\mathrm{R}_{\mathrm{S}} \mathrm{X}_{\mathrm{M}}}{\left(X_{(L S-M)}+X_{M}\right)}$ (real component of $\mathrm{Z}_{\mathrm{TH}}$

$\mathrm{X}_{\mathrm{TH}}=\frac{\mathrm{j} \mathrm{X}_{(\mathrm{Ls}-\mathrm{M})} \mathrm{X}_{\mathrm{M}}}{\mathrm{X}_{(L s-M)}+\mathrm{X}_{\mathrm{M}}}$ (Imaginary Component of $\left.\mathrm{Z}_{\mathrm{TH}}\right\}$

Similarly, $\mathrm{V}_{\mathrm{TH}}=\left[\frac{\mathrm{j} \mathrm{X}_{\mathrm{M}}}{\mathrm{R}_{\mathrm{S}}+\mathrm{j}\left(\mathrm{X}_{(L s-M)}+\mathrm{X}_{\mathrm{M}}\right)}\right] \mathrm{V}_{\mathrm{S}}$

For negligible value of $\mathrm{R}_{\mathrm{s}}$ compared to $\mathrm{j}\left(\mathrm{X}_{(L s-M)}+\mathrm{X}_{\mathrm{M}}\right)$,

$\mathrm{V}_{\mathrm{TH}}=\left(\frac{\mathrm{X}_{\mathrm{M}}}{\left(\mathrm{X}_{(L S-M)}+\mathrm{X}_{\mathrm{M}}\right)}\right) \mathrm{v}_{\mathrm{s}} \quad$ Volts $\quad \ldots 26$

The circuit of fig 8 , reduces to that of fig 9 , in which it is convenience to take $V_{T H}$ as the reference voltage

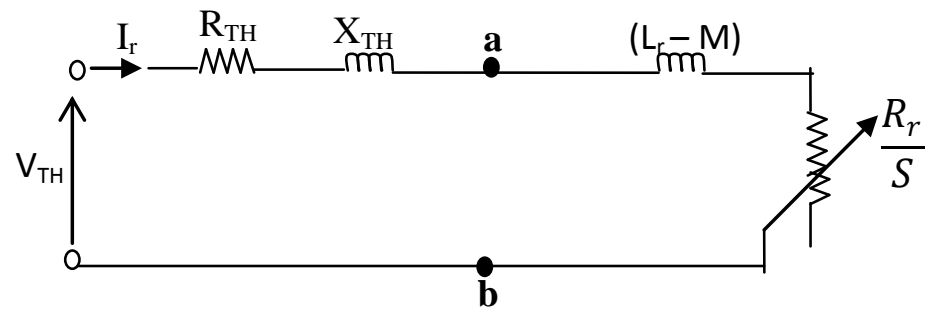

Fig 9 - Thevenin equivalent of 3-phase squirrel cage induction motor circuit model

From fig 9,

$\mathrm{I}_{\mathrm{r}}=\frac{V_{T H}}{\left[\left(R_{T H}+\frac{R_{r}}{S}\right)+\mathrm{j}\left(\mathrm{X}_{\mathrm{TH}}+\mathrm{X}\left(\mathrm{L}_{\mathrm{r}}-\mathrm{M}\right)\right)\right]} \quad \mathrm{A} \quad \ldots 27$

Putting equation 27 into 21 we have;

$\mathrm{Te}=\frac{3 R_{r}}{S \omega_{S}}\left[\frac{\left(V_{T H}\right)^{2}}{\left(R_{T H}+\frac{R_{r}}{S}\right)^{2}+\mathrm{j}\left(\mathrm{X}_{\mathrm{TH}}+\mathrm{X}\left(\mathrm{L}_{\mathrm{r}}-\mathrm{M}\right)\right)^{2}}\right] \quad \mathrm{N}-\mathrm{m} \quad \ldots 28$

Equation 28 is the expression for torque developed as a function of voltage and slip. If the machine parameters of table 1 are properly used for the calculation of the parameters of equation 28 , a simulation plot for the average value of the torque developed at various slip values is obtained as in fig 10. This is termed the motoring region of the machine operation. In this mode of operation, the rotor rotates in the same direction of operating magnetic field produced by the stator currents, the speed is between zero and synchronous speed, and the corresponding slip is between 1.0 and 0 (Eleanya (2015)). The speed of the rotor $\left(\mathrm{N}_{\mathrm{r}}\right)$ is less than the synchronous speed $\left(\mathrm{N}_{\mathrm{s}}\right)$.

\section{Efficiency $\square$ of the squirrel cage induction motor.}

The resistance of a squirrel cage induction motor is fixed, and less compared to its reactance. There is no provision for addition of external resistance. Hence, it is affected by low starting torque with a compensated high efficiency. The efficiency of the machine is given by;

$\xi=\frac{\text { Power output }}{\text { Power input }}$

Neglecting losses, and using derived equations of fig 8/9, we have;

$\xi \%=\frac{\left(R_{r} V_{T H}\right) 100}{S I_{r}\left[\left(R_{T H}+\frac{R_{r}}{S}\right)^{2}+\left(X_{T H}+X_{\left(L_{r}-M\right)}\right)^{2}\right]} \quad \ldots 30$

A plot of the machine efficiency against slip is shown in fig 11.

\section{Discussion of Results/Conclusion}

The equivalent circuit of a three phase squirrel cage induction motor, using the dot convention technique for magnetically coupled circuit has been presented. From the plot of fig 10, at low slip (near synchronous speed), the torque is linear and is directly proportional to slip. Conversely, at large values of slip, the torque is approximately inversely proportional to slip. At synchronous speed $(\mathrm{s}=0)$, current and hence torque decayed to zero. At stand still condition $(s=1)$ of the motor, the rotor speed is zero and the torque produced is $3.80 \mathrm{~N}-\mathrm{m}$. More still from fig 11, the machine efficiency is high and approximately linearly 
proportional to slip, within the range of $0 \leq \mathrm{s} \leq 0.25$. This is the attribute of its low magnetizing current and the corresponding high power factor.

\section{Acknowledgement}

The authors acknowledge God for His protection and guidance. Our cardiac appreciations go to the members of our family for their tolerance and understanding during the research work.

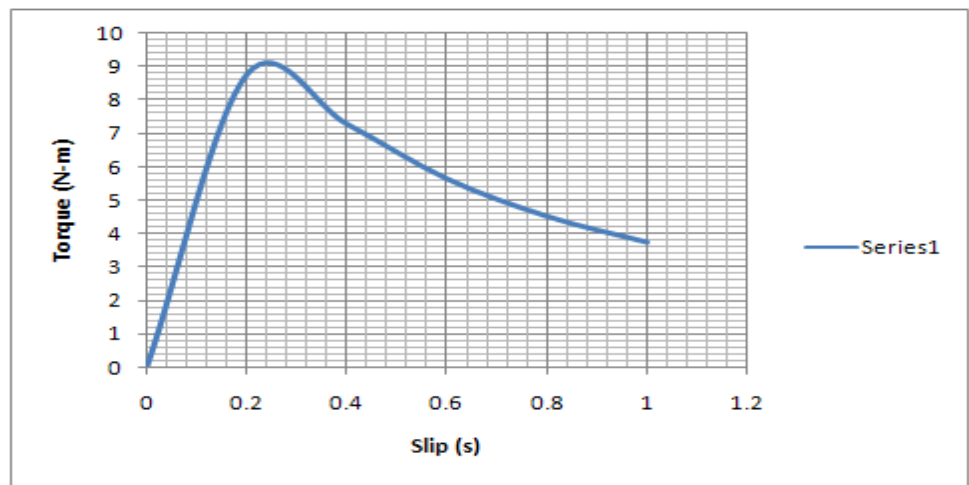

Fig 10: Torque - slip curve of a typical 3 -phase squirrel cage induction motor

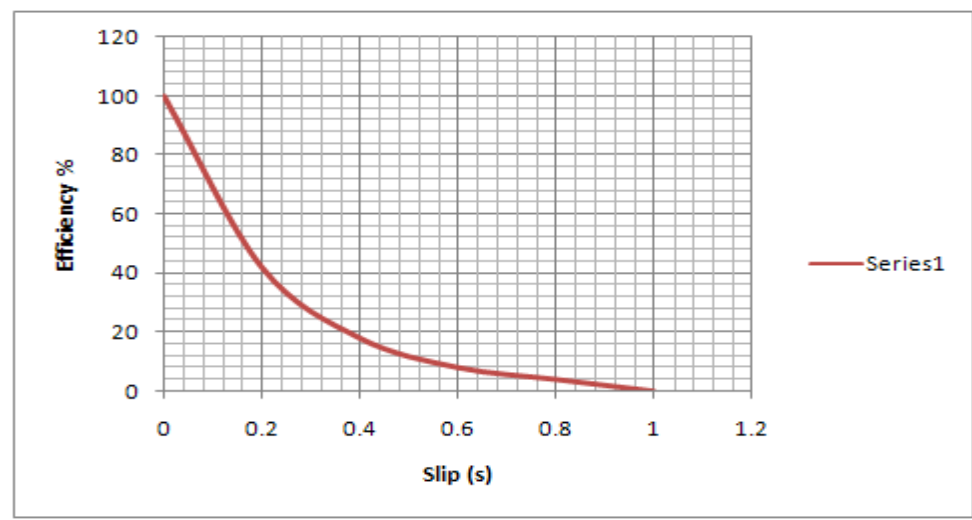

Fig 11: The machine efficiency at motoring mode

\section{References}

[1]. John Bird (2010) "Electrical circuit theory and technology". Published by The Boulevard, Langford lane, Kidlington, Oxford O X 5 IGB, UK, 30 Corporate Drive, suite 400, Burlington, MA 08103 USA(forth edition). page 314.

[2]. Smarajit Ghosh (2007) "Electrical Machines" Published by Dorling Kindersley (India) PVE Ltd. No 482, F.I.E. Patpartgonj, Delhi10092, India (Page 191-192, 486).

[3]. Goggle - Electrical 4 U. Com.

[4]. Eleanya Micheal Ndumlauba (2015) "Comparative Analysis of a transfer field Machine and Induction Machine". - A thesis submitted to the department of Electrical Engineering, University of Nigeria Nsukka (Page 72).

[5]. Charles .K. Alexander and Matthew N.O. Sadiku (2007) "Fundamental of Electric Circuits". Published by Tata Mc Graw-Hill Education Private Limited, of West Patel nagar, New Delhi 10008 (Third edition). Pages $(561,569,570)$

[6]. $\quad$ Fitzgerald A.E, Charles Kingsley, Jr, Stephen D Umans (2003) "Electric Machinary" Published by Mc Graw-Hill, a business Unit of the Mc - Graw - Hill companies, Inc 1221 Avenue of the Americas, New York, NY 10020 